\title{
Солнечный элемент на основе нитевидных нанокристаллов с радиальным гетеропереходом
}

\author{
(C) Н.В. Сибирев ${ }^{1,2,3}$, К.П. Котляр ${ }^{2}$, А.А. Корякин ${ }^{1}$, И.В. Штром ${ }^{3,4}$, Е.В. Убыйвовк ${ }^{3}$, \\ И.П. Сошников ${ }^{4}$, Р.Р. Резник ${ }^{1,4}$, А.Д. Буравлев ${ }^{2,4}$, Г.Э. Цырлин ${ }^{1,2,3,4}$ \\ ${ }^{1}$ Санкт-Петербургский национальный исследовательский университет \\ информационных технологий, механики и оптики, \\ 197101 Санкт-Петербург, Россия \\ ${ }^{2}$ Санкт-Петербургский Академический университет, \\ 194021 Санкт-Петербург, Россия \\ ${ }^{3}$ Санкт-Петербургский государственный университет, \\ 199034 Санкт-Петербург, Россия \\ ${ }^{4}$ Институт аналитического приборостроения Российской академии наук, \\ 190103 Санкт-Петербург, Россия \\ E-mail: NickSibirev@corp.ifmo.ru
}

(Получена 25 апреля 2018 г. Принята к печати 7 мая 2018 г.)

\begin{abstract}
Методом молекулярно-пучковой эпитаксии на подложке $\operatorname{GaAs}(111) \mathrm{B}$, легированной кремнием, были синтезированы массивы нитевидных нанокристаллов (Al, Ga)As с радиальным гетеропереходом, легированные бериллием. Исследование фотоэлектрических свойств полученных структур, проведенное с помощью эмулятора солнечного излучения со стандартным солнечным спектром AM1.5G, показало, что квантовый выход полученного солнечного элемента составляет $4.1 \%$, а кпд $-0.4 \%$.
\end{abstract}

DOI: $10.21883 /$ FTP.2018.12.46758.37

\section{1. Введение}

Соединения на основе полупроводников $\mathrm{A}^{\mathrm{III}} \mathrm{B}^{\mathrm{V}}$ являются одними из наиболее перспективных материалов для создания солнечных элементов. Так, например, рекордное значение эффективности преобразования солнечной энергии, составляющее $46 \%$, было реализовано в солнечной батарее на основе нескольких туннельносвязанных гетеропереходов [1]. Однако для создания такой батареи необходимо проведение множества сложных технологических операций.

Нитевидные нанокристаллы (ННК) обещают со временем стать основой солнечных элементов (СЭ) третьего поколения [2-5]. Во-первых, использование ННК позволяет резко снизить расход особо чистых материалов. Во-вторых, малый поперечный размер ННК позволяет создавать бездефектные гетеропереходы, так как упругие напряжения из-за рассогласования решеток быстро исчезают на боковых стенках ННК. Особенно велик выигрыш для аксиальных гетероструктур в ННК [4,6-8], однако выигрыш для радиальных гетероструктур по сравнению с тонкими пленками тоже заметен, в том числе это позволяет интегрировать полупроводники $\mathrm{A}^{\mathrm{III}} \mathrm{B}^{\mathrm{V}}$ с кремнием $[2,3,9]$. В-третьих, ННК с радиальным $p-n$ - или $p-i-n$-гетеропереходом позволяют независимо оптимизировать условия для поглощения света и разделения заряда, ключевых факторов при создании солнечных элементов и фотодетекторов [2-4]. Кроме того, использование массива ННК уменьшает коэффициент отражения, так как массивы ННК представляют собой отличное антиотражающее покрытие $[3,4,10]$. На данный момент уже достигнута эффективность преобразования солнеч- ной энергии $>10 \%$ на ННК как с радиальным $[11,12]$, так и с аксиальным гетеропереходом [13]. Следует отметить, что пересчет кпд на площадь, занимаемую ННК, является не совсем корректным, так как массивы ННК создают эффект линзы и собирают солнечную энергию с площади, в несколько раз превосходящей их поперечный размер. Поэтому пересчет на единицу площади ННК сильно завышает их эффективность $[3,12]$ и утверждения о преодолении предела Шокли-Квиссера не совсем корректны [12].

Данная работа посвящена исследованию фотоэлектрических свойств полупроводниковых структур на основе массивов НHК (Al, Ga)As с радиальным гетеропереходом, синтезированных с помощью метода молекулярнопучковой эпитаксии (МПЭ) на подложке GaAs кристаллографической ориентации (111)В $n$-типа проводимости.

\section{2. Синтез нитевидных нанокристаллов (Al, Ga)As}

Ростовые эксперименты проводились на установке молекулярно-пучковой эпитаксии Riber Compact21, оснащенной источниками материалов $\mathrm{Al}, \mathrm{Ga}, \mathrm{In}, \mathrm{As}, \mathrm{Au}$, $\mathrm{Si}, \mathrm{Be}, \mathrm{Sb}, \mathrm{N}, \mathrm{P}$. В качестве подложек использовались пластины монокристаллического $n^{+}$-GaAs кристаллографической ориентации (111)B, готовые к эпитаксии (еріready). Синтез ННК с радиальными гетеропереходами осуществлялся в три этапа. Для контроля результатов роста было выращено три образца, на первом реализован только первый этап, на втором первый и второй, на последнем все три этапа. 
$a$
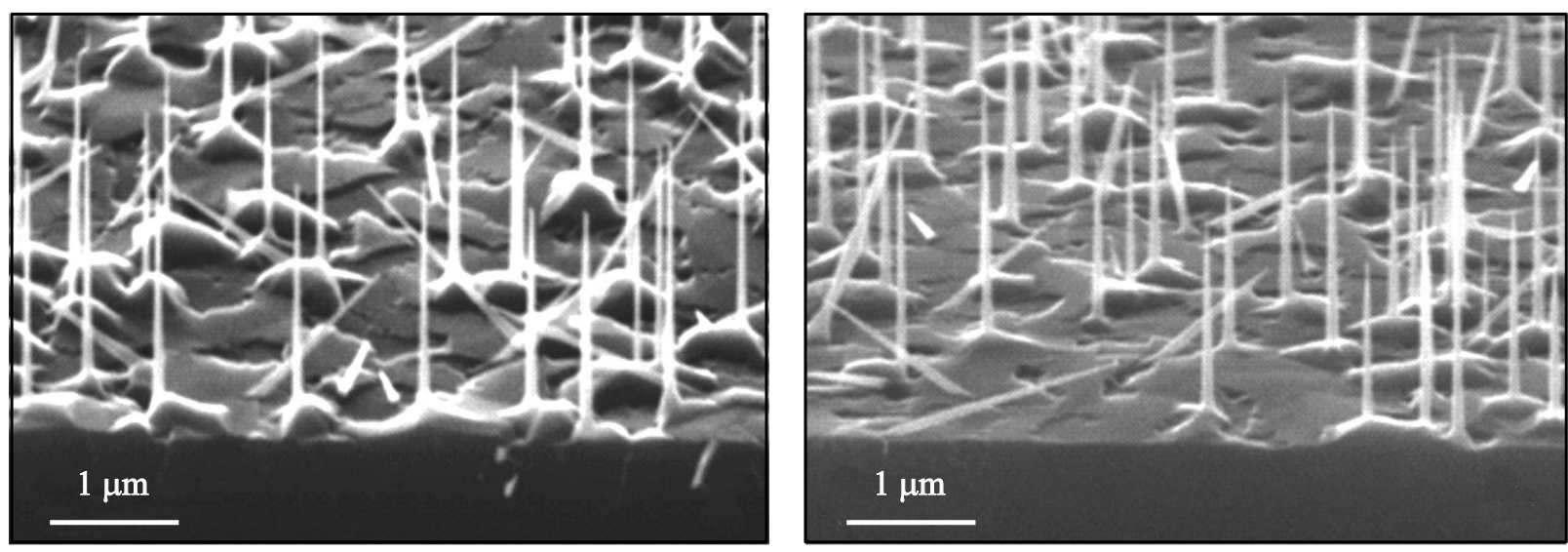

c
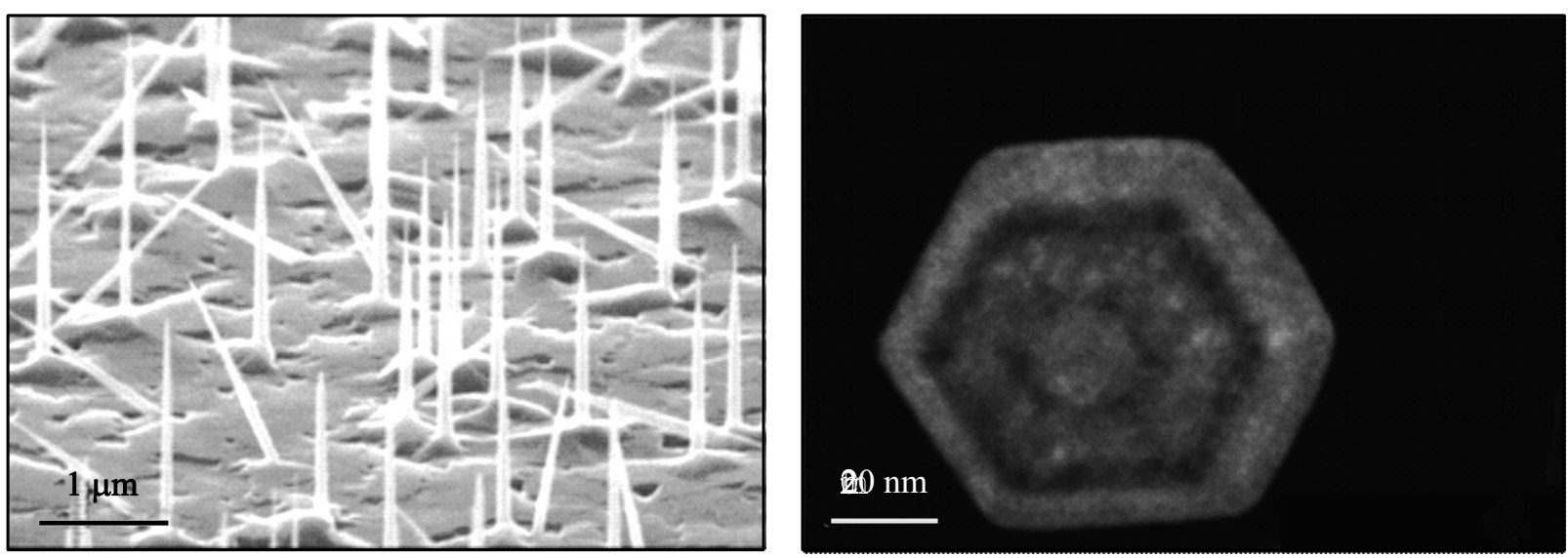

Рис. 1. РЭМ-изображения массива ННК: $a$ - после роста ядра НHК (Al, Ga)As, $b-$ после формирования оболочки НHК GaAs активной области, $c$ - после формирования второй, пассивирующей, оболочки ННК (Al, Ga)As. $d-$ поперечное ПЭМ-изображение одного из полученных ННК.

Рост центральной части ННК (ядра) проводился по стандартному механизму „пар-жидкость-кристалл“ с использованием золота в качестве катализатора роста $[3,5]$. На первом этапе загруженная в камеру металлизации подложка нагревалась до $950^{\circ} \mathrm{C}$ для термической очистки. После осуществлялся рост буферного слоя толщиной $100 \mathrm{Hм}$ (оценка по скорости роста GaAs, легированного кремнием) для выравнивания возможных неоднородностей и шероховатостей поверхности. Затем подложку переносили в камеру металлизации, где при температуре $550^{\circ} \mathrm{C}$ в течение $2 \mathrm{c}$ напыляли тонкий слой золота, после чего перед охлаждением подложки выдерживали паузу в течение 1 мин при той же температуре для формирования нанометровых капель на поверхности. После образования капель подложку переносили в ростовую камеру, где осуществлялся рост ННК $(\mathrm{Al}, \mathrm{Ga}) \mathrm{As}$, легированных Ве. Рост ННК происходил в условиях обогащения мышьяком в течение 20 мин при температуре $480^{\circ} \mathrm{C}$. Потоки галлия и алюминия соответствовали скорости планарного роста 0.8 и $0.2 \mathrm{MC} / \mathrm{c}$ (MC - монослой) для $\mathrm{Ga}$ и $\mathrm{Al}$ соответственно. Состав полученных ННК - сердцевины будущего солнечного элемента - соответствовал 10\% Al. Средний диаметр ННК составил 40 нм. РЭМ-изображения ННК, полученных после первого этапа, представлены на рис. 1, $a$.

Для формирования слоя оболочки ННК температуру опустили до $340^{\circ} \mathrm{C}$, выключили $\mathrm{Al}$, повысили поток мышьяка и продолжали рост в течение 90 с. При такой температуре капля на вершине ННК замерзает и перестает работать как катализатор роста. Диффизия боковых стенок на вершину ННК прекращается, радиальный рост становится доминирующим. Средний диаметр ННК после второго этапа составил 50 нм. РЭМизображения ННК, полученных после второго этапа, представлены на рис. $1, b$.

На третьем этапе температуру роста подняли до $380^{\circ} \mathrm{C}$, включили поток $\mathrm{Al}$, соответствующий скорости планарного роста $0.1 \mathrm{MC} / \mathrm{c}$, скорость осаждения $\mathrm{Ga}$ осталась прежней $0.8 \mathrm{MC} / \mathrm{c}$. Время роста второй оболочки составило $80 \mathrm{c}$. Высота ННК после всех этапов роста составила $(1.4 \pm 0.1)$ мкм, диаметр $(60 \pm 20)$ нм. РЭМ-изображения ННК, полученных после третьего 
этапа, представлены на рис. 1, $c$, плотность массива ННК $6 \cdot 10^{8} \mathrm{~cm}^{-2}$. ПЭМ-изображение поперечного сечения полученного ННК представлено на рис. $1, d$.

\section{3. Методика создания солнечного элемента}

Конструкция солнечного элемента на основе радиальных гетероструктурных $\mathrm{HHK}$ AlGaAs/GaAs/AlGaAs включает нижний омический контакт, планаризующий слой диэлектрика в области вертикальных ННК, вскрытые верхние части ННК и верхние прозрачный и омический контакты. На рис. 2, $a$ представлена схема солнечного элемента с контактами.

В качестве нижнего контакта наносился подслой германия толщиной 5 нм с использованием электроннолучевого испарителя, на который нанесен слой золота толщиной 100 нм путем испарения материала из резистивного испарителя. Перед напылением проводилась обработка поверхности в диодной плазме аргона при давлении $\sim(5-10)$ Па и плотности мощности, варьируемой от 0.01 до $0.5 \mathrm{BT} / \mathrm{cm}^{2}$ в течение $30 \mathrm{c}$. Остаточное давление в камере перед напылением составляло не более $5 \cdot 10^{-4}$ Па. Во время напыления обеспечивалась температура образцов $\sim 80^{\circ} \mathrm{C}$. Быстрый термический отжиг обеспечивает образование сплавных контактов омического типа. Отжиг осуществлялся в бескислородной среде в два этапа: нагрев до температуры $400^{\circ} \mathrm{C}$ в течение 300 с и охлаждение в течение 1200 с. Удельное электрическое сопротивление омических контактов для подложки $n$-типа проводимости составило $0.5 \mathrm{OM} \cdot \mathrm{cm}$, в нашем случае сопротивление было $<0.001 \%$ общего сопротивления структуры.

Для создания верхнего контакта между ННК был осажден слой диэлектрика (полимера SU8) так, чтобы пространство между ННК было полностью им заполнено. Вскрытие верхнего участка ННК от планаризующего диэлектрического слоя осуществлялось в установке плазменного кислородного травления в высокочастотной плазме кислорода в течение $30-300$ c. Перед травлением проводилась оценка методом РЭМ глубины травления на вспомогательных образцах. На рис. 2, $b$ представлено изображение массива ННК после вскрытия на глубину 200 нм. После вскрытия на массив ННК наносился слой оксида индия-олова (ITO) методом высокочастотного магнетронного осаждения на установке Auto360 Boc Edwards. На поверхности образца формируется прозрачный электропроводящий слой оксида индия-олова толщиной от 100 до 200 нм. На рис. 2,c представлено РЭМ-изображение образца после нанесения прозрачного контакта. Для окончательного формирования контактов образец был обработан в диодной плазме аргона при температуре $50^{\circ} \mathrm{C}$, остальные параметры были такими же, как для нижнего контакта. На завершающем этапе проводилось последовательное

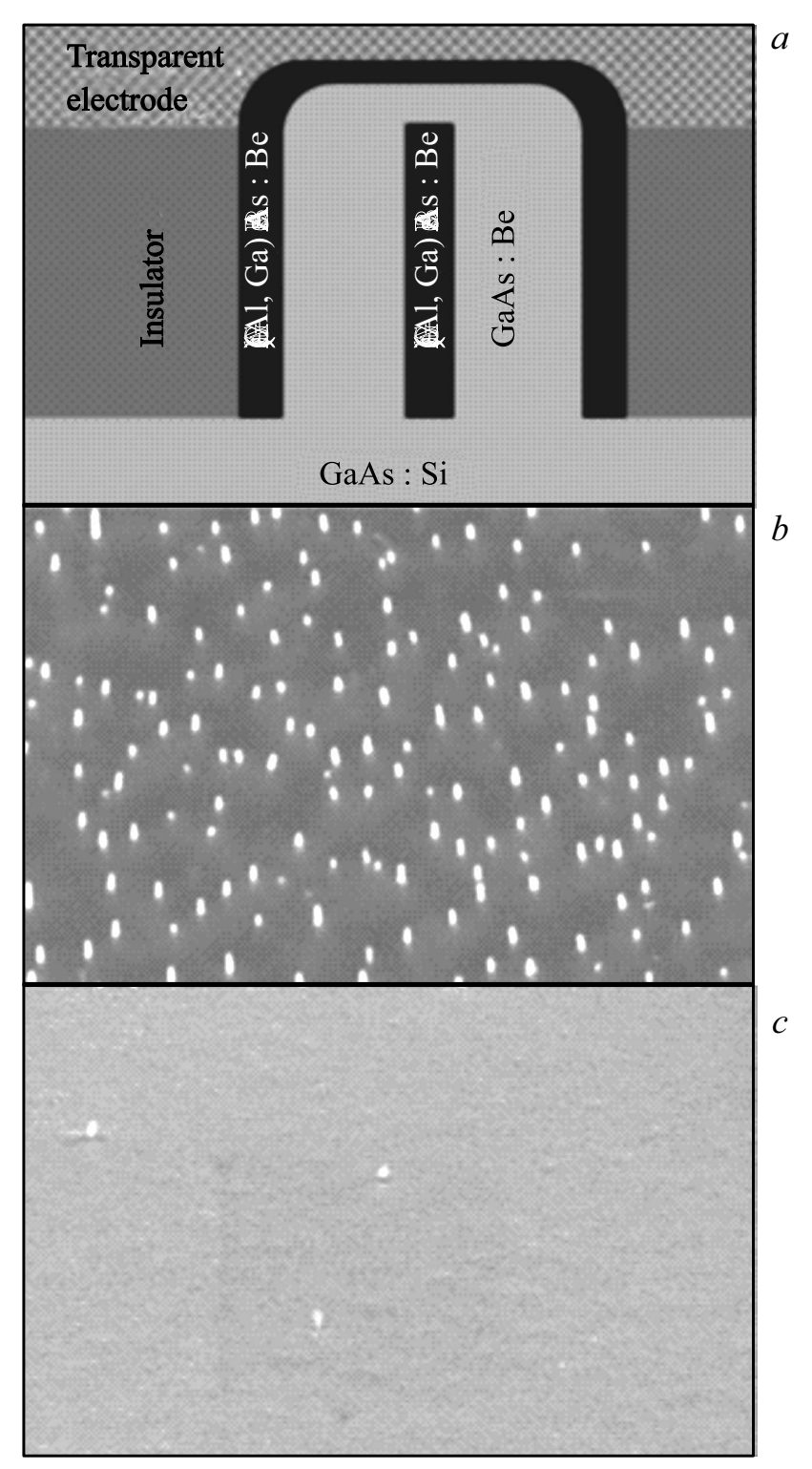

Рис. 2. Схема солнечного элемента $(a)$, РЭМ-изображение массива ННК после вскрытия верхних участков ННК $(b)$, после нанесения планаризующего и контактного слоя на образцы с глубиной вскрытия 200 нм (c).

напыление подслоя никеля толщиной 5 нм с использованием электронно-лучевого испарителя и слоя золота толщиной 100 нм с использованием резистивного испарителя. Удельное электрическое сопротивление верхних контактов составило 100 Ом · см. На рис. 3 приведена фотография полученного солнечного элемента.

\section{4. Результаты измерения свойств солнечного элемента}

Для изучения фотоэлектрических свойств полученной структуры использовалась установка „Спектр-СЭ“, оснащенная источником-измерителем Keithley 2636. Изме- 


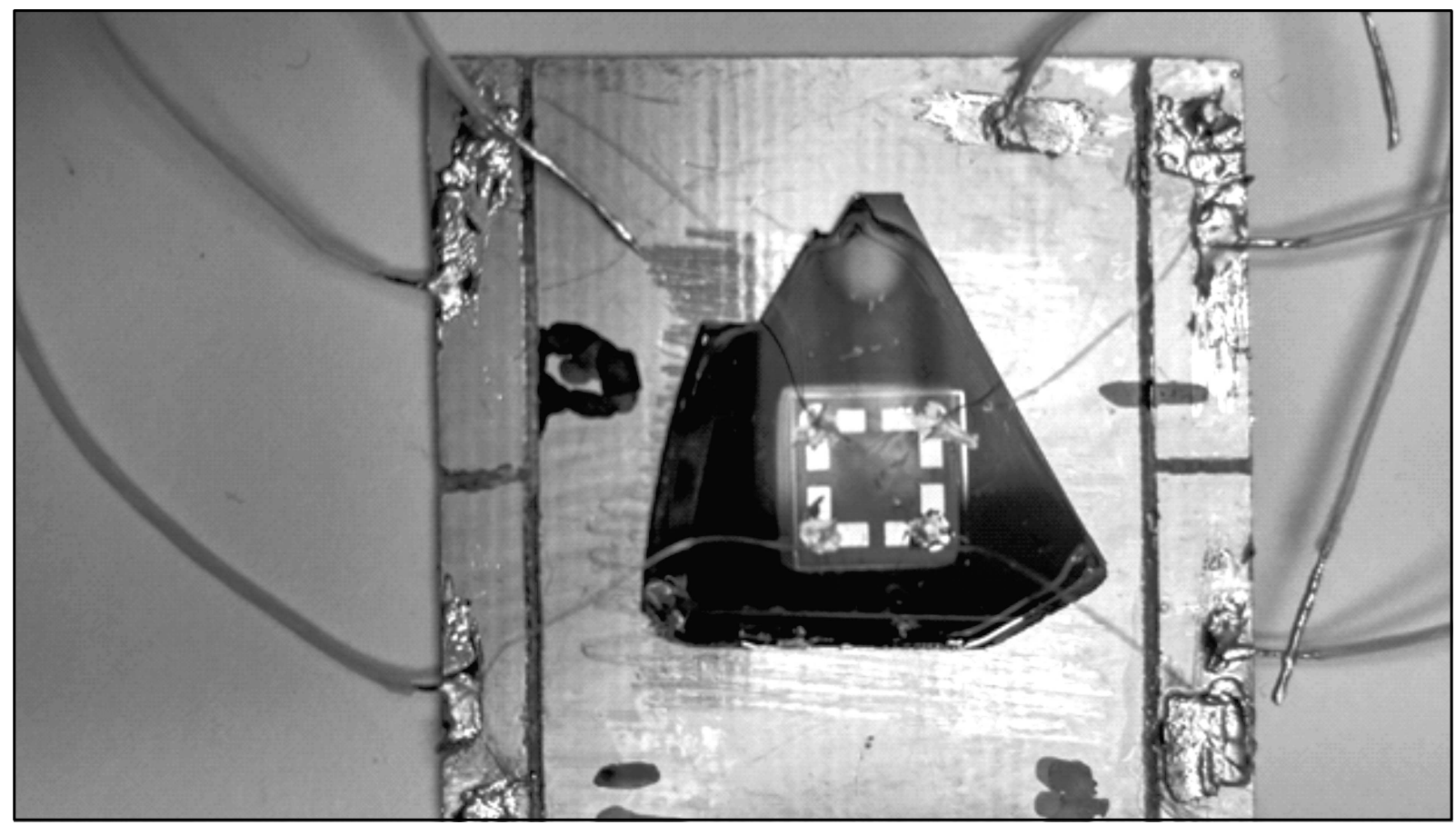

Рис. 3. Фотография солнечного элемента.

рения проводились при комнатной температуре, напряжение варьировалось в диапазоне от -1 до 2 В. В качестве источника солнечного излучения использовался имитатор солнечного излучения класса A Abet Sunlite, model 11002.

На рис. 4 представлена вольт-амперная характеристика (BAX) солнечного элемента. Анализ полученных данных показал, что полученная структура характеризуется следующими параметрами: ток короткого замыкания $I_{S C}=0.01 \mathrm{~A} / \mathrm{cm}^{2}$, напряжение холостого хода $U_{O C}=0.21 \mathrm{~B}$, коэффициент заполнения составил $18 \%$,

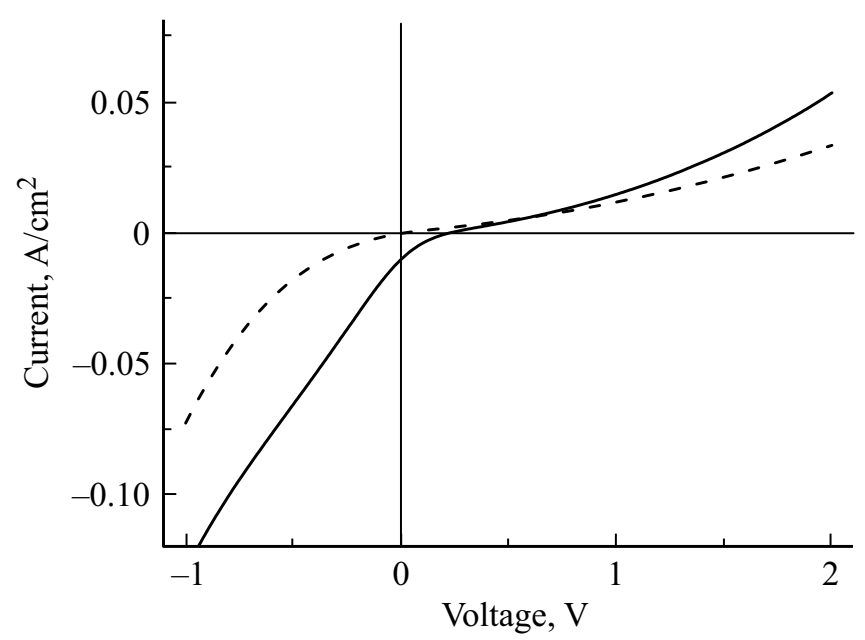

Pис. 4. BAX солнечного элемента на основе НHК (Al, Ga)As при освещении (сплошная линия) и без освещения (штриховая).

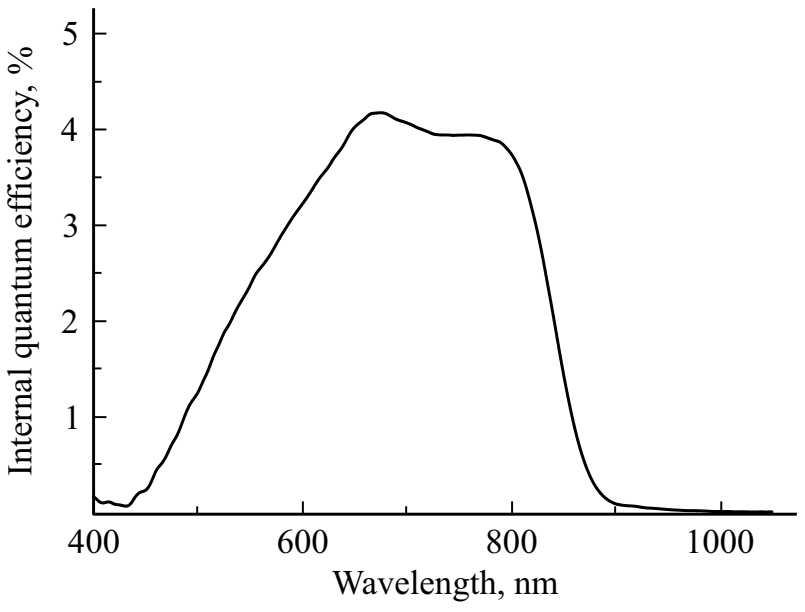

Рис. 5. Спектральная характеристика прототипа оптоэлектронной приборной структуры на основе НHК (Al, Ga)As.

кпд преобразователя составил 0.4\%. Следует отметить, что если перенормировать на площадь, занятую ННК, как было сделано в работах $[3,12]$, то кпд составит $51 \%$, и это выше предела Шокли-Квиссера.

На рис. 5 представлена спектральная характеристика полученного солнечного элемента. Спектральный диапазон чувствительности экспериментального образца составил 450-900 нм, т.е. он такой же, как для HНК (Al, Ga)As с аксиальным гетеропереходом [5]. Максимальный внутренний квантовый выход на длине волны 663 нм составил $\sim 4.1 \%$. Полученный результат 
заметно уступает достигнутому на образцах солнечных элементов, внутренний квантовый выход солнечных элементов на основе НHК GaAs с пассивацией поверхности слоем $\mathrm{InGaP}$ составляет $\sim 10 \%$ [14], для солнечных элементов на основе InP внутренний квантовый выход превосходит 13\% [13]. Для образцов солнечных элементов на основе НHК GaAs без пассивации внутренний квантовый выход составляет 2-5\%[3,4].

Работа выполнена при финансовой поддержке грантами РФФИ № 18-02-01052 и 17-52-53196.

\section{Список литературы}

[1] M.A. Green, K. Emery, Y. Hishikawa, W. Warta, E.D. Dunlop. Progr. Photovolt.: Res. Appl., 24, 905 (2016).

[2] А.М. Можаров, Д.А. Кудряшов, А.Д. Большаков, Г.Э. Цырлин, А.С. Гудовских, И.С. Мухин. ФТП, 50 (11), 1543 (2017).

[3] А.Д. Буравлёв, Д.В. Безнасюк, Е.П. Гильштейн, M. Tchernycheva, A. De Luna Bugallo, L. Rigutti, L. Yu, Yu. Proskuryakov, И.В. Штром, М.А. Тимофеева, Ю.Б. Самсоненко, А.И. Хребтов, Г.Э. Цырлин. ФТП, 47 (6), 797 (2013).

[4] R.R. LaPierre, A.C.E. Chia, S.J. Gibson, C.M. Haapamaki, J. Boulanger, R. Yee, P. Kuyanov, J. Zhang, N. Tajik, N. Jewell, K.M.A. Rahman. Phys. Status Solidi RRL, 7, 815 (2013).

[5] Р.В. Григорьев, И.В. Штром, Н.Р. Григорьева, Б.В. Новиков, И.П. Сошников, Ю.Б. Самсоненко, А.И. Хребтов, А.Д. Буравлев, Г.Э. Цырлин. Письма ЖТФ, 41 (9), 71 (2015) .

[6] Г.Э. Цырлин, И.В. Штром, Р.Р. Резник, Ю.Б. Самсоненко, А.И. Хребтов, А.Д. Буравлев, И.П. Сошников. ФТП, 50 (11), 1441 (2016).

[7] Р.Р. Резник, Г.Э. Цырлин, И.В. Штром, А.И. Хребтов, И.П. Сошников, Н.В. Крыжановская, Э.И. Моисеев, А.Е. Жуков. Письма ЖТФ, 44 (3), 60 (2018).

[8] Н.В. Сибирев. Письма ЖТФ, 41 (5), 1 (2015).

[9] В.В. Лундин, С.Н. Родин, А.В. Сахаров, Е.Ю. Лундина, С.О. Усов, Ю.М. Задиранов, С.И. Трошков, В.Ф. Цацульников. ФТП, 51 (1), 101 (2017).

[10] Л.И. Горай, А.Д. Буравлев, С.А. Поняев. Письма ЖТФ, 41 (13), 16 (2015).

[11] J.V. Holm, H.I. Jørgensen, P. Krogstrup, J. Nygård, H. Liu, M. Aagesen. Nature Commun., 4, 1498 (2013).

[12] P. Krogstrup, H.I. Jørgensen, M. Heiss, O. Demichel, J.V. Holm, M. Aagesen, J. Nygard, A. Fontcuberta i Morral. Nature Photonics, 7, 306 (2013).

[13] J. Wallentin, N. Anttu, D. Asoli, M. Huffman, I. Åberg, M.H. Magnusson, G. Siefer, P. Fuss-Kailuweit, F. Dimroth, B. Witzigmann, H.Q. Xu, L. Samuelson, K. Deppert, M.T. Borgström. Science, 339, 1057 (2013).

[14] G. Mariani, A.C. Scofield, C.-H. Hung, D.L. Huffaker. Nature Commun., 4, 1497 (2013).

Редактор Л.В. Шаронова

\section{Solar cells based on core/shall nanowires}

\author{
N.V. Sibirev ${ }^{1,2,3}$, K.P. Kotlyar ${ }^{2}$, A.A. Koryakin ${ }^{1}$, \\ I.V. Shtrom ${ }^{3,4}$, E.V. Ubiivovk ${ }^{3}$, I.P. Soshnikov ${ }^{4}$, \\ R.R. Reznik ${ }^{1,4}$, A.D. Bouravleuv ${ }^{2,4}$, G.E. Cirlin 1,2,3,4 \\ 1 ITMO University, \\ 197101 St.Petersburg, Russia \\ 2 St. Petersburg Academic University, \\ Russian Academy of Sciences, \\ 194021 St. Petersburg, Russia \\ ${ }^{3}$ St. Petersburg State University, \\ 199034 St.Petersburg, Russia \\ ${ }^{4}$ Institute for Analytical Instrumentation, \\ Russian Academy of Sciences, \\ 190103 St. Petersburg, Russia
}

Abstract Arrays of (Al, Ga)As core/shall nanowires doped with $\mathrm{Be}$ were synthesized by molecular beam epitaxy on a $n$-GaAs(111)B substrate. The study of photovoltaic properties under illumination with a solar simulator (AM1.5G spectrum) demonstrated that the internal quantum efficiency was $\sim 4.1 \%$ and power conversion efficiency was $0.4 \%$. 